\title{
Phytochemical Compounds Present in COVI-MXG Herbal Preparation Inhibits RNA-Dependent RNA Polymerase from SARS-CoV-2: Virtual Screening
}

\section{Poyi, Catherine 0}

Department of Pharmaceutical and Medicinal Chemistry, University of Jos https://orcid.org/00000002-9092-982X

\section{Falang, Kakjing D ( $\sim$ falangkakjing@yahoo.com )}

Department of Pharmacology University of Jos https://orcid.org/0000-0002-0566-3474

\section{Kolawole, Jacob A}

Department of Pharmaceutical and Medicinal Chemistry, University of Jos https://orcid.org/00000002-9257-3345

\section{Research Article}

Keywords: COVID-19, SAR-CoV-2, COVI-MXG, Remdesivir, Hydroxychloroquine, Chloroquine, Lopinavir, Umifenovir, Favipiravir, Zinc

Posted Date: July 1st, 2020

DOl: https://doi.org/10.21203/rs.3.rs-38115/v1

License: (1) (i) This work is licensed under a Creative Commons Attribution 4.0 International License. Read Full License 


\section{Abstract}

Background: COVID-19 pandemic disease, caused by coronavirus 2 (SARS-CoV-2) is expressed as severe acute respiratory syndrome. There are currently no proven effective therapeutic agents or vaccines against the virus. However clinical management includes infection prevention, control measures, supportive care using drug therapy based on previous scientific experience, pathophysiology and pharmacology of the drug. Some of the therapeutic agents exploited include; antiviral and antimalarial agents (remdesivir, hydroxychloroquine, chloroquine, lopinavir, umifenovir, favipiravir, and oseltamivir), Zinc and selenium. There are claims of herbal preparations with palliative or therapeutic effects. The novel formulation of herbal preparation, COVI-MXG for the management of Covid-19 contains a unique combination of five (5) plants. In silico studies was carried out using robust methods and software to evaluate the plant constituents to determine its possible antiviral activity, safety and pharmacokinetic profile.

Results: Pharmacokinetic predictions showed phytochemicals with varying degrees of gastrointestinal absorption rates and blood brain barrier permeability. Toxicity class fall between 3 and 5 with high $\operatorname{LD}_{50}$ values.

Conclusions: When compared with the listed therapeutic agents, the phytochemical compounds present in COVI-MXG showed varying degrees of binding affinities for SARS-CoV-2 (7BV2.pdb) better than the drugs currently in use at the target sites. The preparation contains high concentration of Zinc and other micronutrients.

\section{Background}

Coronavirus disease 2019 (COVID-19), caused by severe acute respiratory syndrome coronavirus 2 (SARS-CoV-2) first originated in Central China and has now spread to almost all countries of the world. The disease is responsible for extensive mortality with serious public health implications and there are no clinically approved vaccines or specific therapeutic drugs available at the moment ${ }^{[1,2]}$. SARS-CoV-2 requires the viral RNA-dependent RNA polymerase (RdRp) for replication which is a target for antiviral drugs such as Remdesivir and Favipiravir ${ }^{[3]}$. As a result of this challenge, it is thought that herbal medicines and/or purified natural products may be helpful in guiding development of novel and effective drugs against the virus. It was reported that between 85 to $92 \%$ of patients in some cities in China resort to herbal drugs in addition to other remedies ${ }^{[4,5]}$. Earlier reports show that even though the herbal medications are effective relatively good safety margin, the mechanism of activity is poorly understood. It however thought that the activity might be through viral inhibition ${ }^{[6]}$.

From the forgoing and given the impact of the pandemic, there is the urgent search for effective treatment using innovative strategies. One of such techniques involves computational approaches $[7,8]$. 
This approach is advantageous, as it drastically cuts down on the time-consuming animal and in vitro assay laboratory work ${ }^{[9]}$. In addition it reduces costs associated with the attempt to physically screen large banks of compounds or of plant extracts for biological activity ${ }^{[10]}$. The strategy is particularly helpful in the attempt to tame the rampaging COVID-19 pandemic as it can highlight compounds which can then be evaluated for in vitro effectiveness and toxicity using cell-based assays before being subjected to other investigations such as animal and clinical trials ${ }^{[4]}$.

The herbal formulation COVI-MXG contains Monodora myristica, Xylopia aethiopica, Gongronema latifolium, Viscum album and Garcinia kola. There is no report in the literature to our knowledge to the effect that this combination of plants and in the proportions has ever been documented for use in the management of Covid 19.

The study used virtual screening to evaluate inhibitory effect of the phytochemical compounds present in COVI-MXG on SARS-CoV-2 RdRp.

\section{Methods}

\section{Methods}

All methods used in this study were entirely In Silico.

\section{Hardware, Ligand Library and Target Preparation}

All the computational analysis/ screening were done using x64-based PC, windows 10 Pro, with 32-Bit operating system.

A compound library of 21 phytochemical constituent (table 1) contained in COVI-MXG were downloaded from PubChem ${ }^{[11]}$ and optimized in discovery studio 4.5 visualizer ${ }^{[12]}$. Also included in the ligand library were 9 therapeutic compounds currently in use for the treatment of COVID-19; Lopinavir, Remdesivir, Ritonavir, Umifenovir, Favipiravir, Oseltamivir, Quinine, Chloroquine and Hydroxychloroquine.

Table 1: Phytochemical compounds used in molecular docking studies 


\begin{tabular}{|c|c|}
\hline \multirow[t]{3}{*}{ dora myristica } & Limonene \\
\hline & $\alpha$ - pinene \\
\hline & $\alpha$-phellandrene \\
\hline \multirow[t]{9}{*}{ ia aethiopica } & $\beta$-pinene \\
\hline & $\beta$-phellandrene \\
\hline & $\alpha$-pinene \\
\hline & $\gamma$-terpinene \\
\hline & Trans- pinocarveol \\
\hline & p- cymene \\
\hline & 1,8- cineole \\
\hline & Germacrene D \\
\hline & $\alpha$ - cadinol \\
\hline \multirow[t]{9}{*}{ malbum } & Syringin \\
\hline & Sinapic acid \\
\hline & Myricetin \\
\hline & Kaempferol \\
\hline & Chlorogenic acid \\
\hline & Protocatechuic acid \\
\hline & Quercetin \\
\hline & Ferulic acid \\
\hline & Rosmarinic acid \\
\hline nia kola & Kolaviron \\
\hline
\end{tabular}

The crystal structure of the SARS- CoV-2 target with pdb code 7BV2.pdb was downloaded from the Protein Data Bank (pdb) (https://www.rcsb.org/). The pdb file was opened in WordPad, water molecules and its original ligands (remdesivir) eliminated and file re-saved.

\section{Virtual Screening}

The library of ligands were docked into the protein target and the binding affinities determined in Autodock Tools using PyRx 0.8 package ${ }^{[13]}$ and Autodock Vina ${ }^{[14]}$. A grid box (x: 89.4261, y: 86.5813, z: 98.8772) with dimensions (Angstrom) (x: 44.1528 y: 48.0231 z: 25.0000) was employed. The ligands were inputted as Structure-data file (.sdf) while the target protein was inputted as a Protein Databank File (.pdb file) which was converted to the acceptable .pdbqt file for Autodock Vina. Molecular interactions between protein target and ligands were analysed using PyMol ${ }^{[15]}$ and discovery studio 4.5 visualizer ${ }^{[12]}$.

\section{In Silico ADMETox Analysis}

SwissADME ${ }^{[16]}$ was used to study the absorption and distribution of the phytochemicals while accessing; bioavailability score, Blood- brain barrier permeability, and gastrointestinal tract absorption. ProTox-II ${ }^{[17]}$ was used to study the rodent oral toxicity of the phytochemicals. Parameters such as carcinogenicity, hepatotoxicity, immunotoxicity, mutagenicity and cytotoxicity were assessed. 
Not applicable

\section{Results}

Phytochemicals present in COVI-MXG showed varying degrees of binding affinities for SARS-CoV-2 (7BV2.pdb) as shown by the change in binding energy $(\mathrm{Kcal} / \mathrm{mol})$ in Table 2. The molecules were seen to exhibit different types of interactions including hydrogen- bonding, covalent bonding, alkyl and van der waal's force interactions (Figure 1). Major phytochemical in Garcinia kola showed the highest binding affinity followed closely by phytochemicals in Viscum album. These molecules were seen to have been better than current therapies. Three (3) pytochemicals in Xylopia aethiopica had a better binding affinity than Favipiravir but the same with umifenovir while two (2) in Monodora myristica had the same binding affinity as Favipiravir (Table $1 \& 2$ ). The molecules were observed to have docked properly within the target without global changes (Figure 2)

Toxicity predictions (Table 3 ) showed phytochemicals with varying degrees of gastrointestinal absorption rates, blood brain barrier permeability and bioavailability. Toxicity class fell between 3-5 with high $\mathrm{LD}_{50}$ except for P-cymene with a predicted toxicity class of 1 and a predicted rodent $L_{50}$ of $3 \mathrm{mg} / \mathrm{Kg}$.

Table 2: Binding affinities of phytochemical constituents to SARS-CoV-2 target (7BV2.pdb). 


\begin{tabular}{|l|l|l|}
\hline Phytochemicals & Binding Affinity (Kcal/mol) & Rank \\
\hline Kolaviron & -8.1 & 1 \\
\hline Quercetin & -7.9 & 2 \\
\hline Kaempferol & -7.9 & 2 \\
\hline Myricetin & -7.9 & 2 \\
\hline Chlorogenic acid & -7.4 & 3 \\
\hline Rosmarinic acid & -7.2 & 4 \\
\hline Ritonavir & -6.4 & 5 \\
\hline Remdesivir & -6.3 & 6 \\
\hline Quinine & -6.2 & 7 \\
\hline Ferulic acid & -6.1 & 8 \\
\hline Syringin & -6.1 & 8 \\
\hline Hydroxychloroquine & -6.0 & 9 \\
\hline Oseltamivir & -5.7 & 10 \\
\hline Lopinavir & -5.7 & 10 \\
\hline$\alpha$ - cadinol & -5.6 & 11 \\
\hline Protocatechuic acid & -5.5 & 12 \\
\hline Sinapic acid & -5.4 & 13 \\
\hline Umifenovir & -5.3 & 14 \\
\hline$\gamma$ - terpinene & -5.3 & 14 \\
\hline p- cymene & -5.3 & 14 \\
\hline Germacrene D & -5.3 & 14 \\
\hline Favipiravir & -5.2 & 15 \\
\hline Limonene & -5.2 & 15 \\
\hline$\alpha$ - phellandrene & -5.2 & 15 \\
\hline$\beta$ - phellandrene & -5.0 & 16 \\
\hline Chloroquine & -4.6 & 17 \\
\hline$\alpha-$ pinene & -4.5 & 19 \\
\hline Trans- pinocarveol & -4.4 & 20 \\
\hline $1,8-$ cineole & -4.4 & \\
\hline$\beta$ - pinene & -4.2 & 19 \\
\hline & & \\
\hline
\end{tabular}

Molecules in bold are currently used in the therapeutic management of Covid- 19

Table 3: ADMETox Predictions of Phytochemical Constituents present in COVI-MXG 


\begin{tabular}{|c|c|c|c|c|c|c|}
\hline hytochemicals & $\begin{array}{l}\text { GI } \\
\text { absorption }\end{array}$ & $\begin{array}{l}\text { BBB } \\
\text { Permeant }\end{array}$ & $\begin{array}{l}\text { *Bioavailability } \\
\text { Score }\end{array}$ & $\begin{array}{l}* * \text { Predicted } \\
\text { Toxicity Class }\end{array}$ & $\begin{array}{l}\text { Predicted } \\
\mathrm{LD}_{50}(\mathrm{mg} / \mathrm{kg})\end{array}$ & Toxicity End points \\
\hline olaviron & Low & No & 0.17 & 4 & 2000 & Inactive \\
\hline uercetin & High & No & 0.55 & 3 & 159 & Immunotoxicity \\
\hline aempferol & High & No & 0.55 & 5 & 3919 & Immunotoxicity \\
\hline lyricetin & Low & No & 0.55 & 3 & 159 & Immunotoxicity \\
\hline hlorogenic acid & Low & No & 0.11 & 5 & 5000 & Inactive \\
\hline osmarinic acid & Low & No & 0.56 & 5 & 5000 & Immunotoxicity \\
\hline emdesivir & & & & 4 & 1000 & Inactive \\
\hline uinine & & & & 3 & 263 & Immunotoxicity \\
\hline erulic acid & High & Yes & 0.56 & 4 & 1772 & Inactive \\
\hline yringin & Low & No & 0.55 & 5 & 4000 & Inactive \\
\hline ydroxychloroquine & & & & 4 & 1240 & $\begin{array}{l}\text { Immunotoxicity \& } \\
\text { mutagenicity }\end{array}$ \\
\hline - cadinol & High & Yes & 0.55 & 5 & 2830 & Immunotoxicity \\
\hline rotocatechuic acid & High & No & 0.56 & 4 & 2000 & Carcinogenicity \\
\hline inapic acid & High & No & 0.56 & 4 & 1772 & Inactive \\
\hline - terpinene & Low & Yes & 0.55 & 5 & 2500 & Inactive \\
\hline - cymene & Low & Yes & 0.55 & 1 & 3 & Carcinogenicity \\
\hline ermacrene D & Low & No & 0.55 & 5 & 5000 & Immunotoxicity \\
\hline imonene & Low & Yes & 0.55 & 5 & 4400 & Inactive \\
\hline - phellandrene & Low & Yes & 0.55 & 6 & 5700 & Inactive \\
\hline - phellandrene & Low & Yes & 0.55 & 5 & 5000 & Inactive \\
\hline hloroquine & & & & 4 & 311 & $\begin{array}{l}\text { Immunotoxicity \& } \\
\text { mutagenicity }\end{array}$ \\
\hline - pinene & Low & Yes & 0.55 & 5 & 3700 & Inactive \\
\hline rans- pinocarveol & High & Yes & 0.55 & 4 & 1800 & Inactive \\
\hline 8- cineole & High & Yes & 0.55 & 5 & 2480 & Inactive \\
\hline pinene & Low & Yes & 0.55 & 5 & 4700 & Inactive \\
\hline
\end{tabular}

BBB permeant: Blood brain barrier permeability; GI absorption: Gastrointestinal tract absorption

Molecules in bold are currently used in the therapeutic management of COVID-19

* Bioavailability $(\mathrm{F})=0.85=$ Polar surface area (PSA) $\leq 75 \mathrm{~A}(2)$,

$$
\begin{aligned}
& =0.56=\mathrm{PSA} 75-150 \mathrm{~A} \mathrm{(2)} \\
& =0.11=\mathrm{PSA} \geq 150 \mathrm{~A}(2)
\end{aligned}
$$

**Toxicity Class; 1 : Extremely toxic

2: Moderately toxic

3: Slightly toxic

4- 6: Non-toxic/ Low toxicity

\section{Discussion}

Current clinical management includes antiviral agents (remdesivir, hydroxychloroquine, chloroquine, lopinavir, umifenovir, favipiravir, and oseltamivir), anti-oxidants (vitamin C) and micro nutrients (Zinc and Selenium). Though these drugs are still undergoing clinical trial in different countries, there is reported 
scientific backing for their use. This is therefore the bases for their use as reference molecules in the comparison and in silico study.

Bioactive compounds present in COVI-MXG through docking analysis have shown varying degree of molecular interaction with the protein target SARS-CoV-2 RdRp (7BV2.pdb) (Figure 1) which could inhibit the replication of the virus. Some of the interactions and better binding affinities observed in this study is supported by some of the antiviral activities of the molecules. Studies have shown the antiviral activities of Kaempferol ${ }^{[18]}$, Limonene ${ }^{[19]}$, and myricetin ${ }^{[20]}$ against coronavirus, and herpes simplex virus.

Furthermore, Monoterpenes such as $\mathrm{y}$-terpinene, a-pinene, $\mathrm{p}$-cymene, and 1, 8-cineole have been shown to have a better antiviral activity and low toxicity when in a mixture than as single entities [21].

Structure activity relationship could be said to have an effect on position of binding among the phytochemicals as can be seen by remdesivir and kolaviron (Figure 2a \& b). Most of the other smaller phytochemical compounds were seen to share the same binding pocket with hydroxchloroquine (Figure $2 c$ and d).

In silico ADMETox profiling of the phytochemicals showed a very promising low toxicity profile for COVIMXG. This is because most of the molecules were of low toxicity except p-cymene which had a toxicity class 1 prediction and an $L_{50}$ of $3 \mathrm{mg} / \mathrm{kg}$. The toxicity of p-cymene should not pose a problem seeing as it is only $7.3 \%$ of Xylopia aethiopica fruit oil.

Phytochemicals such as $\alpha$ - and $\beta$-Pinene which exhibited considerable binding affinities with the molecular target but much lower than the current drug management of COVID-19 (Table 2), have been reported to possess antiviral and antibacterial activities ${ }^{[19,22]}$.

The formulation of COVI-MXG would afford a synergistic effect, seeing as it contains Gongronema latifolium which has an appreciable amount of Zinc ${ }^{[23]}$ and the zinc ionophore activity of quercetin ${ }^{\text {[24] }}$ which showed a higher binding affinity (Table 2). Zinc has been shown to play an important role in the inhibition of coronavirus RNA polymerase ${ }^{[25]}$.

\section{Conclusion}

Pharmacokinetic predictions showed phytochemicals with varying degrees of gastrointestinal absorption rates and blood brain barrier permeability. Toxicity class ranged from 3-5 with a high $L_{50}$. Phytochemicals exhibited considerable binding affinities with the molecular target. The formulation of COVI-MXG would afford a synergistic effect, since Gongronema latifolium contains high level of Zinc and the zinc ionophore activity of quercetin, which showed a very high binding affinity. Also Zinc has been shown to play an important role in the inhibition of coronavirus RNA polymerase. This formulation is safe, and has shown good activity against the coronavirus 2 (SARS-CoV-2).

\section{List Of Abbreviations}


7BV2.pdb: pdb code for crystal structure of the SARS-CoV-2 target

BBB permeant: Blood- brain barrier permeability

GI absorption: Gastrointestinal tract absorption

COVID-19: Coronavirus disease 2019

$\mathrm{LD}_{50}$ : Lethal Dose $50 \%$

pdb: Protein Data Bank

RNA: Ribonucleic Acid

SARS-CoV-2: Severe Acute Respiratory Syndrome Coronavirus 2

Sdf: Structure-data file

RdRp: RNA-dependent RNA polymerase

\section{Declarations}

Ethics approval and consent to participate:

Not applicable

Consent for publication:

Not applicable for that section

\section{Availability of data and materials:}

These have been reported and cited in the methodology part of the manuscript

\section{Conflict of interest:}

The authors declare no conflict of competing interests

\section{Funding:}

No funding received

\section{Authors' Contributions:}

FKD and KJA did the conception and design of the work. PCO did the Acquisition, analysis and interpretation of the data. FKD drafted the manuscript. All authors substantively revised the manuscript, read and approved the final copy of the manuscript for submission. 
Acknowledgements:

We acknowledge University of Jos for the use of facilities.

\section{References}

1. Li H, Liu SM, Yu XH, Tang SL, Tang CK (2020). Coronavirus disease 2019 (COVID-19): current status and future perspectives. Int $\mathrm{J}$ Antimicrob Agents 105951. Advance online publication. https://doi.org/10.1016/j.ijantimicag.2020.105951

2. Ali I, Alharbi O (2020). COVID-19: Disease, management, treatment, and social impact. Sci Total Environ 728, 138861. Advance online publication. https://doi.org/10.1016/j.scitotenv.2020.138861

3. Yin W, Mao C, Luan X, Shen DD, Shen Q, Su, H et al (2020). Structural basis for inhibition of the RNAdependent RNA polymerase from SARS-CoV-2 by remdesivir. Science eabc1560. https://doi.org/10.1126/science.abc1560

4. Mani JS, Johnson JB, Steel JC, Broszczak DA, Neilsen PM, Walsh KB, Naiker M (2020). Natural product-derived phytochemicals as potential agents against coronaviruses: A review. Virus Res 284, 197989. https://doi.org/10.1016/j.virusres.2020.197989

5. Yang Y, Islam M S, Wang J, Li Y, Chen X (2020). Traditional Chinese medicine in the treatment of patients infected with 2019-new coronavirus (SARS-CoV-2): a review and perspective. Int J Biol Sci 16(10), 1708-17. https://doi.org/10.7150/ijbs.45538

6. Li SY, Chen C, Zhang HQ, Guo HY, Wang H, Wang, L et al (2005). Identification of natural compounds with antiviral activities against SARS-associated coronavirus. Antiviral Res 67(1), 18-23. https://doi.org/10.1016/j.antiviral.2005.02.007

7. Ekins S, Mestres J, Testa B (2007). In silico pharmacology for drug discovery: methods for virtual ligand screening and profiling. Br J Pharmacol 152(1), 9-20. https://doi.org/10.1038/sj.bjp.0707305

8. Yuan H, Ma Q, Ye L, Piao G (2016). The Traditional Medicine and Modern Medicine from Natural Products. Molecules 21(5), 559. https://doi.org/10.3390/molecules21050559

9. Valerio Jr LG (2012). Application of advanced in silico methods for predictive modelling and information integration. Expert Opin Drug Metab Toxicol 8(4), 395-398. https://doi.org/10.1517/17425255.2012.664636

10. Chen Y, de Bruyn Kops C, Kirchmair J, (2017). Data resources for the computer-guided discovery of bioactive natural products. J Chem Inf Model 57(9), 2099-2111. https://doi.org/10.1021/acs.jcim.7b00341

11. Kim S, Chen J, Cheng T, Gindulyte A, He J, He S et al (2019). PubChem 2019 update: improved access to chemical data. Nucleic Acids Res 47(D1), D1102-D1109.

https://doi.org/10.1093/nar/gky1033

12. BIOVIA (2016). Discovery Studio Modeling Environment, Release 2017, San Diego: Dassault Systems. 
13. Dallakyan S, Olson AJ (2015). Small-Molecule Library Screening by Docking with PyRx. Methods Mol Biol 1263, 243-250. https://doi.org/10.1007/978-1-4939-2269-7_19

14. Trott O, Olson AJ (2010). AutoDock Vina: Improving the speed and accuracy of docking with a new scoring function, efficient optimization, and multithreading. J Comput Chem 31(2), 455-461. https://doi.org/10.1002/jcc.21334

15. DeLano WL (2002). Pymol: An open-source molecular graphics tool. CCP4 Newsletter on Protein Crystallography, 40(1), 82-92.

16. Daina A, Michielin O, Zoete V (2017). SwissADME: a free web tool to evaluate pharmacokinetics, drug-likeness and medicinal chemistry friendliness of small molecules. Scientific Reports, 7, 42717. https://doi.org/10.1038/srep42717

17. Drwal MN, Banerjee P, Dunkel M, Wettig MR, Preissner R (2014). ProTox: a web server for the in silico prediction of rodent oral toxicity. Nucleic Acids Res 42(Web Server issue), W53-W58. https://doi.org/10.1093/nar/gku401

18. Schwarz S, Sauter D, Wang K, Zhang R, Sun B, Karioti A et al (2014). Kaempferol derivatives as antiviral drugs against the 3 a channel protein of coronavirus. Planta Medica, 80(2-3), 177-182. https://doi.org/10.1055/s-0033-1360277

19. Astani A, Schnitzler P (2014). Antiviral activity of monoterpenes beta-pinene and limonene against herpes simplex virus in vitro. Iran J Microbiol 6(3), 149-155.

20. Ortega JT, Serrano ML, Suárez Al, Baptista J, Pujol FH, Cavallaro LV et al (2019). Antiviral activity of flavonoids present in aerial parts of Marcetia taxifolia against Hepatitis B virus, Poliovirus, and Herpes Simplex Virus in vitro. EXCLI Journal 18, 1037-1048. https://doi.org/10.17179/excli20191837

21. Astani A, Reichling J, Schnitzler P (2010). Comparative Study on the Antiviral Activity of Selected Monoterpenes Derived from Essential Oils. Phytother Res 24, 673-679. https://doi.org/10.1002/ptr.2955

22. Salehi B, Upadhyay S, Erdogan Orhan I, Kumar Jugran A, Jayaweera S, Dias D et al (2019). Therapeutic Potential of $\alpha$ - and $\beta$-Pinene: A Miracle Gift of Nature. Biomolecules 9(11), 738. https://doi.org/10.3390/biom9110738

23. Balogun ME, Besong EE, Obimma JN, Mbamalu OS, Djobissie SFA (2016). Gongronema Latifolium: A Phytochemical, Nutritional and Pharmacological Review Journal of Physiology and Pharmacology Advances 6(1), 811-824. https://doi.org/10.5455/jppa.1969123104000

24. Dabbagh-Bazarbachi H, Clergeaud G, Quesada IM, Ortiz M, O'Sullivan CK, Fernández-Larrea JB (2014). Zinc ionophore activity of quercetin and epigallocatechin-gallate: from Hepa 1-6 cells to a liposome model. J Agric Food Chem 62(32), 8085-8093. https://doi.org/10.1021/jf5014633

25. te Velthuis AJ, van denWorm SH, Sims AC, Baric RS, Snijder EJ, van Hemert MJ (2010). Zn(2+) inhibits coronavirus and arterivirus RNA polymerase activity in vitro and zinc ionophores block the replication of these viruses in cell culture. PLoS Pathog 6(11): e1001176. https://doi.org/10.1371/journal.ppat.1001176 


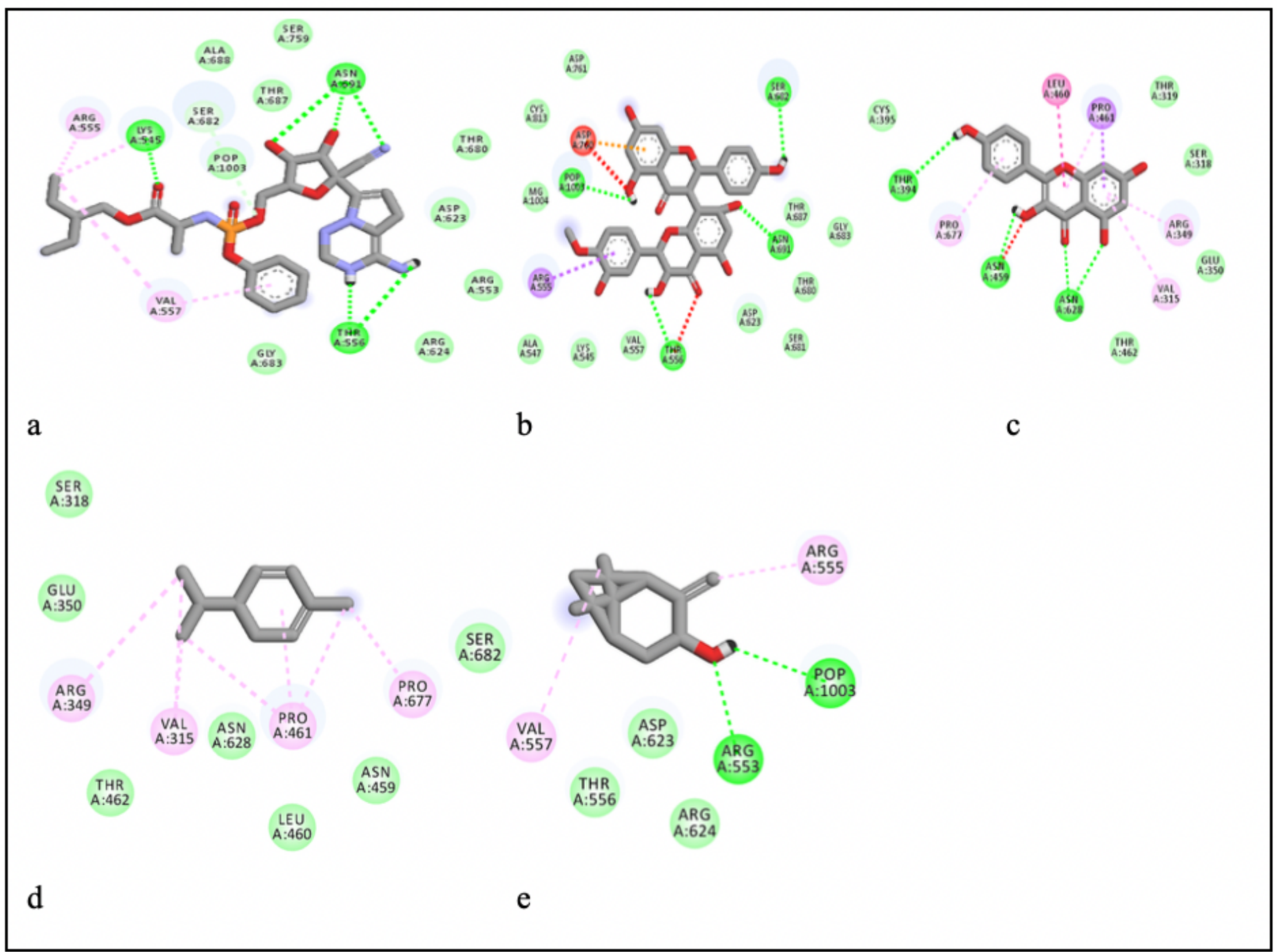

\section{Figure 1}

2D binding interactions of Remdesivir (a), Kolaviron (b), kaempferol (c), a- phellandrene (d) and Transpinocarveol (e) to the active site residues of SARS-CoV-2 (7BV2.pdb). Ligands are shown in stick forms while amino acid residues are shown in disc forms. Hydrogen- bond interaction with amino acid main chain are indicated by green discontinuous lines, green colored discs shows van der waal's interaction, pink discs shows alkyl interactions while purple discs shows pi-sigma interactions. Discs and lines shown in red colour represent unfavourable bumps and interactions. 


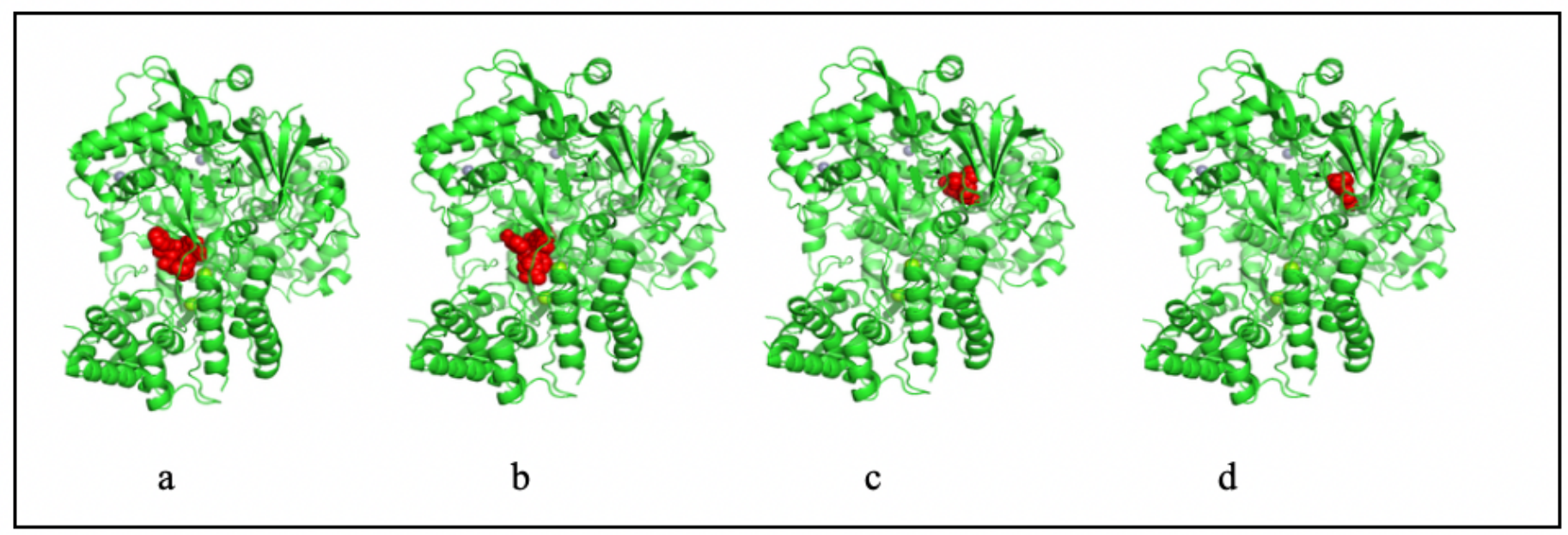

Figure 2

Ribbon representation of 7BV2.pdb in complex with Remdesivir (a), Kolaviron (b), Hydroxychloroquine (c), and a-cadinol (d). There was no global changes observed in the conformation of the target upon binding of Ligands. Ligands are shown in red spheres while target (7BV2.pdb) is shown in green ribbons. 